\title{
URBAN GEOGRAPHY EVOLVING: TOWARD AN EVOLUTIONARY URBAN GEOGRAPHY
}

\author{
Russell C. WeAver \\ Department of Environmental Studies, MS GIS Program, University of Redlands, Redlands, CA, USA
}

Manuscript received: July 24, 2013

Revised version: January 7, 2014

WeAver, R.C., 2014. Urban geography evolving: Toward an evolutionary urban geography. Quaestiones Geographicae 33(2), Bogucki Wydawnictwo Naukowe, Poznań, pp. 7-18, 1 table. DOI 10.2478/quageo-2014-0012, ISSN 0137-477X.

\begin{abstract}
AвSTRACT: Despite growing interest in the application of evolutionary concepts to research questions in human geography, the literature is largely characterised by metaphors or analogies that are disconnected from a broader evolutionary theoretical framework. This paper takes initial steps toward developing such a framework for the subfield of urban geography by defining critical elements and relationships from Darwinian and multilevel selection theories. It then synthesises those components in an application to the issues of urban blight and disorder, to demonstrate how an evolutionary understanding of urban spatial phenomena - an "evolutionary urban geography" - can produce new insights for managing complex processes.
\end{abstract}

KEY WORDS: evolutionary urban geography, urban change, urban decline, evolution

R.C. Weaver, University of Redlands, MS GIS Program, Department of Environmental Studies, 1200 E. Colton Avenue, PO Box 3080, Redlands, CA, 92373 USA; e-mail: russell_weaver@redlands.edu

\section{Introduction}

It is difficult to deny the growing interest in applying Darwinian principles and evolutionary thinking to problems of social science (Jeffrey 1996; Essletzbichler, Rigby 2007). For example, recent work sets forth to generalise Darwinism to the areas of social and economic evolution (Hodgson, Knudsen 2010); to develop a general framework for economics and public policy grounded in evolutionary theory (Wilson, Gowdy 2013); and to identify the conditions under which cooperative social institutions evolve and adapt to their environments over time (Heinrich et al. 2004; Gintis et al. 2005; Wilson et al. 2013). These illustrations, as well as a plenitude of related literature (e.g., Bowles 2006; Dunbar 2007; van den Bergh, Gowdy 2009), reasonably foretell of a steady decline in the erstwhile reluctance of some social scientists to draw on evolutionary theory in their research (see: Pumain 1998; Lustick 2011).

Yet in this era of emerging evolutionary accession in the social sciences, many appeals to evolutionary principles, for example in human geography within the subdiscipline of evolutionary economic geography (EEG), are made exclusively for metaphorical purposes (Essletzbichler, Rigby 2007). As Boschma and Frenken (2006: 274) observe, much of this work essentially pays "lip service" to evolutionary thinking and concepts, while neglecting to advance a general framework firmly rooted in evolutionary theory. Absent such a framework, continuing to practice the piecemeal adoption of evolutionary vocabulary in the social sciences plausibly results in inconsistent usage of biological terms, and, by extension, the downgraded validity and reliability 
of those terms outside of their native disciplines (Essletzbichler, Rigby 2007). In what is perhaps a prefigurative look at the future of EEG, however, several scholars are beginning to synthesise the subdiscipline's extant metaphorical applications in order to outline an agenda, and propose approaches, for establishing a general Darwinian evolutionary framework that can be applied more uniformly across the field (Boschma, Frenken 2006; Essletzbichler, Rigby 2007).

Parallel developments cannot be discussed for urban geography (Ghitter, Smart 2009). In fact, despite a voluminous body of scholarship on urban change and dynamics (Megbolugbe et al. 1996; Wyly 1999; Pitkin 2001; Somerville et al. 2009), much of which ostensibly describes evolutionary processes (Allen 1997; Wyly 1999), an urban counterpart to EEG has not emerged within the human geography literature. As an example, consider that at the time of this writing, executing a Google Scholar search on the exact phrase "evolutionary urban geography" yields a single result (Ghitter, Smart 2009), compared to 1,440 results for "evolutionary economic geography". ${ }^{1}$ And, as is the case with much work in EEG, that one result uses evolutionary terminology more for metaphorical and analogical purposes than for constructing a general framework (e.g., Boschma, Frenken 2006; Essletzbichler, Rigby 2007). As is discussed in subsequent sections, the lack of movement in this direction is potentially due to a turn in the urban literature toward self-organisation (e.g., Allen 1997). Yet while some authors proffer self-organisation as a general theory of evolution unto itself, it is easily shown to depend on Darwinian processes (Hodgson, Knudsen 2010).

That a general Darwinian-evolutionary project has not been undertaken in urban geography is therefore surprising on one hand, but somewhat unsurprising on the other. With respect to the former, many classic and contemporary urban geography models specify the elements and interactions that give rise to urban sprawl (Torrens 2006) and neighbourhood succession (e.g., Hoyt 1939; Grigsby et al. 1987), among other things. Clearly these phenomena represent changes to complex population systems, which

The Google Scholar search mentioned here was last executed on 22 May 2013. collectively intimate the operation of evolutionary forces (Hodgson, Knudsen 2010). Importantly, though, it is widely held that such changes are multi-causal and highly interdependent (Glaeser, Gyourko 2005). In this sense, it is not wholly surprising that urban geography has avoided a direct systematic appeal to generalised Darwinism to date; for evolutionary explanations of the Darwinian variety tend to be causal (Okasha 2006), and many phenomena of interest to urban geographers lack universally held causal explications (e.g., Wagenaar 2007).

Given this observation, is it therefore appropriate for urban geographers to resist an evolutionary "turn" à la the movement under way in economic geography (e.g., Boschma, Frenken 2006)? This essay argues that the answer to this question is an emphatic "no". Indeed, I submit that evolutionary theory has much to offer urban geographers in terms of organising concepts and thinking critically about causality - although I by no means claim to resolve long-standing issues regarding the multi-causal nature of certain urban phenomena. Rather, this paper contextualises key propositions from selected urban change and decline literature in Darwinian and evolutionary terms, which leads me to advocate for the establishment of an "evolutionary urban geography" grounded in Darwinian evolution in gener$\mathrm{al}$, and multilevel selection theory in particular. To arrive at this outcome, the paper first introduces and defines concepts that are crucial to conceiving of Darwinian evolution in hierarchical population structures. It then briefly surveys selected urban change literature from an evolutionary perspective in search of new insights into the processes that generate manifestations of urban decline, especially blight and disorder. The exercise is intended to chart a course toward a general theoretical framework that can underlie an evolutionary urban geography.

\section{Preliminaries: evolution and multilevel selection theory}

By now it is common for individuals outside of the biological sciences to attribute the "discovery" of evolution to Charles Darwin, even though rival theories pre- and post-date Dar- 
win's seminal work (e.g., Mayr 2001; Hodgson, Knudsen 2010). That Darwin's theory achieved such prominence and popularity relative to alternative explanations is due not simply to the overwhelming evidence establishing it as fact (Mayr 2001), but also to its exceedingly generalisable and flexible nature (Dawkins 2003; Wilson 2007, 2011).

To appreciate this point, consider the three basic ingredients of Darwinian evolution: variation, selection, and heritability (Mayr 2001; Wilson 2007). First, suppose that there exists some population of discrete entities, all members of which possess some character, $z$. Further assume that $z$ is distributed differentially across entities in the population, and that $z$ is positively correlated to the "fitness" of entities. That is to say, $z$ varies at the micro-level within the population, and this variation has population-level consequences (Wilson 2007; Lustick 2011). For example, if "fitness" is taken to mean offspring, then entities with high levels of $z$, because of the positive (hypothesised) correlation between $z$ and offspring, will produce more progeny on average. Suppose now that offspring are sufficiently similar to parent entities, such that parents with high $z$ transmit relatively high $z$ to their offspring and likewise for parents with low $z$. Stated alternatively, $z$ is heritable. It follows that over time the average level of $z$ will increase in the population of entities, insofar as high- $z$ entities produce more heirs than low- $z$ entities. Thus high $z$ is selected for in the population.

Apart from being necessarily oversimplified, the preceding narrative describes the general process by which evolutionary change occurs in a single-level population (Okasha 2006; Wilson 2007; Lustick 2011). Crucially, observe that "this view of life" requires population thinking - populations are comprised of heterogeneous members, and individual-level dissimilarities (eventually) produce changes in the total population (Mayr 2001). In this regard, population thinking and Darwinian evolution suggest gradualism, or the idea that population changes are non-instantaneous, as there exists some degree of fixity in member characteristics (Mayr 2001; Essletzbichler, Rigby 2007). For instance, it is only after a sufficient amount of reproduction that the population $z$ level increases in the foregoing example, via selection for high $z$.
Lewontin (1970) writes that this sort of evolution by selection rests on three conditions: (1) variation in a particular trait; (2) associated differences in fitness; and (3) heritability. While these "Lewontin conditions" (Okasha 2006) effectively echo Darwin's principles of evolution, they also have considerable utility for generating unambiguous mathematical statements. Namely, if, as before, $z$ is a trait owned by entities in a given population, then for evolution by selection to occur with respect to $z$ it must be the case that:

1. $\operatorname{Var}(z) \neq 0$;

2. $b_{z} \neq 0$;

3. $h \neq 0$;

where $\operatorname{Var}(z)$ is the statistical variance in trait $z$, $b_{z}$ is the coefficient derived by performing a regression of entity fitness on $z$ (i.e., fitness depends on $z$ ), and $h$ is the coefficient derived by performing a regression of offspring $z$ on parent $z$ (i.e., $z$ is heritable) (Okasha 2006).

These so-called Lewontin conditions enumerate the basic information requirements for studying evolution by selection: a known population that is comprised of discrete entities; a trait of interest that can be measured for all entities in the population and their heirs; and a way to conceptualise fitness for the population entities. Nonetheless, note that from an evolutionary outsider's perspective the Lewontin conditions have few (obvious) implications for the possible role of socio-spatial context in evolutionary change. To wit, the conditions seem to imply only that entities interact in a single population, and that those entities with absolute fitness advantages modulo a particular beneficial trait will adapt to a given environment more successfully than their fellow entities, such that the population eventually comes to represent its best adapted members (e.g., Wilson 2004).

Picture now a population in which constituents reside in spatially delimited groups, and that one's success in the population depends not only on its own attributes, but also on how well those attributes interact with homologous traits in one's fellow group members. For example, in the urban social world one's quality of life hinges on both its own cooperation with local rules, and the extent to which one's neighbours cooperate with those rules (e.g., Bourne 1981; Grigsby et al. 1987; Wilson 2011). In the case of the urban com- 
mons, for instance, it has been shown that high neighbourhood cooperation with property maintenance rules influences local non-co-operators to cooperate, and mutatis mutandis for low neighbourhood cooperation (Weaver, Bagchi-Sen [in press]). The number of (non)co-operators in the total population therefore evolves under group pressures. Hence, for such circumstances there is more to the evolution-by-selection story than the (single-level variety of the) Lewontin conditions presented above (Okasha 2006). Indeed, one can envisage the possibility of Darwinian selection operating at multiple levels (Wilson 2007). ${ }^{2}$ Stated alternatively, total evolutionary change in a given hierarchical population can be a function of individual and group attributes (Okasha 2006). This notion is a cornerstone of multilevel selection theory (MLS).

Briefly, MLS assumes that populations are hierarchically organised, such that population entities are nested into groups wherein local interactions take place (Okasha 2006; Wilson et al. 2013). More precisely, MLS literature reiteratively describes groups as "collectives" in which "particles" engage in fitness-affecting interactions (Okasha 2006). By assuming a hierarchically organised population structure, MLS theory thus allows for the possibility of collective-level ("group") selection (Okasha 2006; Wilson, Wilson 2007). Collective-level selection is important for overcoming the "fundamental problem of social life", which is that traits contributing to particle fitness tend to undermine collective fitness (Wilson, Wilson 2007). A classic example of this problem is Hardin's (1968) tragedy of the commons, or the idea that when all individuals in a population have open access to a single resource, the natural incentive to gain an advantage over conspecifics leads all individuals to over-harvest the resource relative to its sustainable level, thereby diminishing its future availability and productivity. To resist the urge to over-harvest would place a given entity at a disadvantage relative to conspecifics, all of whom would gain from the lo-

Lewontin (1970) was well aware of multilevel selection. The use of the phrase "single-level variety of the Lewontin conditions" here is intended to describe only the context in which the conditions were presented above, and not to imply that Lewontin's work (1970) did not consider the possibility of MLS. calised cost borne by the cooperative entity (Wilson, Wilson 2007).

Generalising this logic, at the single-particle level, evolutionary theory appears to disfavour the emergence of pro-social or group-beneficial behaviour, given that such behaviours are individually costly and susceptible to free-riding (Wilson, Wilson 2007). At the collective level, by contrast, it is far less problematic to see how cooperation might evolve. Namely, if collectives are to "survive" in the total population, then intra-collective particle competition like that in Hardin's (1968) tragedy must be selected against (Wilson 2007, 2011). For collectives whose particles, say, destroy fitness-enhancing resources will be less "fit" in the overall population than fellow collectives whose particles cooperate to sustain their resources over time. It follows that selection at the group level can steadily reduce the presence of the former, self-regarding types within the environment. In other words, collective-level selection gradually favours cooperation amongst interacting particles (Wilson 2007, 2011; Wilson, Wilson 2007).

MLS theory therefore proposes that selection operates simultaneously at multiple levels of a hierarchically structured population (Okasha 2006). Analogous to the single, particle-level scenario from earlier, then, this implies that at a given collective level of selection, collectives must (1) possess some fitness-affecting character, (2) which varies across collectives in the population, and (3) which is heritable. Concerning the latter of these, collective heritability can occur in two varieties: either, (a) collectives give rise to new collectives, or (b) collectives give rise to new particles whose characteristics are similar to those found in the parent collectives (Okasha 2006). The implication is that in addition to the (now multilevel) information requirements of the Lewontin conditions, evolutionary studies of hierarchical populations must specify a "focal" unit of selection - collectives or particles.

Together these elements form the beginnings of a framework for studying change in complex urban population systems. Prior to moving forward, however, it is constructive to articulate "one of the most important distinctions in evolutionary theory": the distinction between ultimate and proximate causation (Lloyd et al. 2011: 
13). Ultimate causation relates to the function of a given attribute, or why it exists. Proximate causation relates to the attribute's mechanism, or how it comes to manifest (Lloyd et al. 2011). As mentioned above, urban decline is largely seen as a multi-causal process, the source(s) of which can often go undetected (e.g., Wagenaar 2007). In other words, it has proven difficult to consistently explicate the cause(s) of decline or its various indicators, such as "urban blight" (Shlay, Whitman 2006; Weaver 2013). When viewed through the ultimate-proximate lens, though, one can begin to categorise the many possible causes of blight. For example, it is fairly straightforward to imagine that a proximate cause of the problem -i.e., a mechanism that facilitates it - is insufficient property maintenance or failure to cooperate with local rules and norms that relate to property upkeep (Skogan 1986; Brueckner, Helsley 2011; Weaver 2013). At the same time, the ultimate cause of the problem, or the reason why it has become adapted to urban society, might involve its association with structural issues such as poverty and the uneven socio-spatial distribution of capital (e.g., Pacione 2003).

Collectively the aforementioned concepts, which originate in the Darwinian and MLS sectors of evolutionary theory, and together with the ultimate-proximate causation distinction, can provide a working evolutionary framework for urban geography. The remainder of the paper supports this statement by synthesising illustrative arguments from the literature on urban decline, particularly those concerning the related issues of blight and disorder, within an evolutionary urban geography context.

\section{Urban change and neighbourhood decline}

A comprehensive review of the literature on urban change and decline is beyond the scope of this essay, and interested readers should refer to, inter alia, Grigsby et al. (1987), Megbolugbe et al. (1996), Pitkin (2001), Pacione (2003), or Somerville et al. (2009) for more depth on the topics that follow. Here the focus is narrowly on a handful of matters that concern manifestations of urban decline, particularly "blight" (Weaver,
Bagchi-Sen 2013; Weaver 2013) and "disorder" (Ross, Mirowsky 1999; Vitale 2008).

Theories of (multiple) deprivation hold that complex urban problems such as property abandonment and poor housing conditions, and even crime, are caused by poverty (Pacione 2003). More specifically, economic deprivation usurps much of an individual's power to alter his or her own quality of life, and this leads to individual-level decision-making that is incongruent with some aggregate-level (e.g., city or neighbourhood) paradigm of social control (Pacione 2003; Vitale 2008). These individual-aggregate tensions are observed in things such as poorly maintained homes, overgrown lawns, and the presence of graffiti, trash, and debris in visible public and private spaces (Ross, Mirowsky 1999). For simplicity and facility of exposition, it is henceforth assumed that these and related conditions can be collapsed into the associated concepts of "disorder" and "blight", and that they can be approximated by substandard real property conditions (e.g., Weaver 2013).

The view that poverty - particularly spatially concentrated poverty - in cities is responsible for the existence of substandard property conditions is rather widely held in the social sciences (Pacione 2003; Grigsby et al. 1987; Megbolugbe et al. 1996; Glaeser, Gyourko 2005). The argument is that individual-level lack of economic resources makes property maintenance a low priority and thus an insufficiently taken action among low-income households, and this gives rise to blight or disorder in urban neighbourhoods (Megbolugbe et al. 1996). Over time, these visible (as well as the latent) conditions of neighbourhood poverty motivate those households with adequate means to relocate (Wagenaar 2007). During this process the residual composition of such neighbourhoods becomes increasingly impoverished. Only households that lack the resources necessary to relocate remain (Glaeser, Gyourko 2005); and any incoming households likely enter only because their location decisions are severely constrained by low incomes, and housing tends to be relatively inexpensive in blighted areas (Krumm, Vaughan 1976; Weaver, Bagchi-Sen [in press]). As a result, poverty progressively concentrates in blighted urban spaces, and property conditions therein continue to deteriorate (Glaeser, Gyourko 2005). 
Within this context, one can argue that poverty is perhaps the underlying reason for blight and disorder (Grigsby et al. 1987). Nevertheless, the more immediate reason for such problems is the deficient levels of property investment or maintenance just described (e.g., Brueckner, Helsley 2011; Weaver 2013). Importantly, urban scholars invariably recognise that deficient property maintenance is highly vulnerable to spatial externalities (Bourne 1981; Grigsby et al. 1987; Megbolugbe et al. 1996). In other words, because property values are known to be spatially interdependent, blighted properties tend to devalue all properties with which they share a neighbourhood (Bourne 1981). Devaluation, in turn, reduces the returns to local property maintenance, and this potentially influences neighbouring households - including those that previously maintained their properties at or exceeding some optimal level - to abstain from the activity (Megbolugbe et al. 1996). This implies that household poverty is not a necessary condition for the creation of all individual-level blight or disorder. Rather, households may choose to cooperate (maintain property) or not cooperate (not maintain property) based on their spatial locations within relatively cooperative or non-cooperative neighbourhoods (Bourne 1981).

Along these lines we have at least two causal explanations for the creation of blight or disorder within an urban area. Adherents to the first, poverty-based explanation tend to include critical urban geographers who follow the political economy approach (Harvey 1976; Pacione 2003). Namely, understanding urban decline in capitalist societies begins by recognising that capitalist competition for urban space inevitably results in geographically uneven development, as capital is distributed to locations where the gains to be made are greatest (Pacione 2003). The explicit causal process at work in this explanation is succinctly described by Pacione (2003: 316) as follows:

"The differential use of space by capital in search of profit creates a mosaic of inequality at all geographic levels from global to local. Consequently, at any one time certain countries, regions, cities and localities will be in the throes of decline as a result of the retreat of capital investment, while others will be experiencing the impact of capital inflows. At the metropolitan scale the outcome of this uneven development process is manifested in sociospatial variations in life quality and, in particular, in the poverty, powerlessness, and polarization of disadvantaged residents (emphasis added)."

It is clear from this passage that the political economy perspective regards inequality as a precursor to neighbourhood disorder. Uneven development produces a class of disadvantaged residents, and, in sequence, conditions of localised poverty cause urban problems such as blight and disorder to appear in spaces of retreating capital (Pacione 2003). Although the term 'evolution' does not feature in this narrative, the view bears certain hallmarks of an evolutionary explanation - minimally, it describes a causal process by which change occurs in a complex population system. However, if the change of interest to researchers and policymakers is in the level of the non-cooperative property maintenance "trait" in the urban population, then it can be shown that the resemblant evolutionary reasoning reaches an impasse when filtered through the concepts from above.

Recall that a given trait is subject to (Darwinian) evolutionary forces when (1) it varies across entities in the relevant population, (2) variations in the trait have differential impacts on fitness, and (3) the trait is heritable (Lewontin 1970). In the political economy vision, non-cooperative property maintenance behaviour need not be heritable. Rather, it depends on the spaces of capital, such that current patterns of blight or disorder are explained by current patterns of investment, and not by prior property maintenance behaviour per se (e.g., Pacione 2003). Restating this in terms of the Lewontin (1970) conditions from above, performing a regression of household non-cooperative behaviour for some time period, $t$, on household non-cooperative behaviour for some prior period, $t-m$, can indeed output a nonzero coefficient $h$; but this relationship would likely be spurious. For period $t$ non-cooperative behaviour is determined by capital availability in $t$, and does not causally depend on non-cooperative behaviour during period $t-m$. The same argument applies at the neighbourhood level. Hence the political economy approach implies that change in non-cooperative maintenance behaviour is not itself evolutionary, but is a by-product of glob- 
ally-influenced changes in the flows of capital at different geographic scales. Using the language from above, whereas a comprehensive functional and mechanistic understanding of a given attribute enables policymakers to become "wise managers" of the processes that generate it (Wilson 2007: 11), in the political economy view there is no specification of a mechanism that can be targeted for intervention. Rather, the implication is that structural policy reforms are needed to counteract uneven development and eradicate economic inequality. This will presumably cancel out the function of non-cooperative maintenance behaviour in the environment.

The second causal explanation for patterns of blight/disorder introduced above emphasises that the spatial interdependence of neighbourhood property values significantly influences household maintenance decisions. Specifically, because substandard property conditions contribute to the devaluation of all properties in a given neighbourhood, they therefore reduce the returns to maintenance for all local households (Bourne 1981). In this sense, patterns of blight and disorder are the result of households interacting in localised prisoner's dilemmas, wherein one's decision to cooperate or defect is contingent on the expected or observed actions of one's neighbours (Megbolugbe et al. 1996). From this perspective, the problem is an emergent phenomenon that arises when households interact in space. Accordingly, the urban change and decline literature has shown an expanding interest in self-organisation (Allen 1997; Pumain 1998; Batty, Xie 1999).

Self-organisation refers to the ability of interacting components to (often inadvertently) determine the structure of their parent system (Hodgson, Knudsen 2010). Stated differently, in a self-organised system, pattern or order emerges from the many interactions of the system's constituent elements, where the resultant patterns tend to be unreflective of component-level intentions (Pumain 1998; Hodgson, Knudsen 2010; Lustick 2011). For example, household-level decisions to relocate from a city centre are almost certainly not directed toward setting off a chain reaction whereby poverty concentrates in urban centres, and inner-city neighbourhoods deteriorate both physically and economically; but it is from such particle-level interactions that system-wide patterns of decline frequently emerge (Grigsby et al. 1987; Glaeser, Gyourko 2005).

Without a doubt the self-organisation paradigm holds significant explanatory power over many complex emergent phenomena (Hodgson, Knudsen 2010), including patterns of urban change (Pumain 1998; Batty, Xie 1999). Yet while some scholars proffer self-organisation as a general theory of evolution unto itself (Witt 1997), it is necessary to recognise that explaining the emergence of pattern and order does not necessarily explain the survival and adaptability of that emergent order over time (Hodgson, Knudsen 2010). On the contrary, the (in)ability of an emergent pattern to adapt to its host environment is subject to, and dependent upon, the Darwinian process of selection (Hodgson, Knudsen 2010). Even key scholars of the self-organisation paradigm, particularly in urban studies, acknowledge that self-organised patterns depend on Darwinian evolution (Allen 1997).

Thus, as with the political economy approach, the self-organisation view is not a fully evolutionary explanation of change in intra-urban non-cooperative property maintenance behaviour. Unlike the earlier explanation, though, the Lewontin (1970) conditions are satisfied non-cooperative maintenance behaviour (1) varies across space, (2) differentially affects household and neighbourhood utility, and (3) tends to be path-dependent (heritable) at both the particle and collective scales (e.g., Grigsby et al. 1987). Here what is missing is an ultimate cause, or an account of why emergent patterns adapt to their environments (e.g., Hodgson, Knudsen 2010). I therefore turn to evolutionary urban geography to see if the approach can produce new insights and policy implications.

\section{Evolutionary urban geography and neighbourhood decline}

Admittedly I have heretofore surveyed only a small and selected fraction of the literature on urban and neighbourhood decline (for more thorough reviews, see: Megbolugbe et al. 1996; Pitkin 2001; Somerville et al. 2009). Nonetheless, doing so allowed for identification of two alternative 
explanations for the creation of urban blight/disorder, neither of which imparts a comprehensive causal understanding (proximate and ultimate) of the issue. In response to this, Table 1 synthesises key pieces from each aforementioned explanation within an evolutionary urban geography framework based on the core principles and concepts unpacked throughout this essay.

To begin, note that the interest is in explaining the evolution of non-cooperative (i.e., blight-generating) property maintenance behaviour in a given urban area at the household (particle) level. This is the same goal that was pursued in the foregoing explorations of the political economy and self-organisation explanations of the phenomenon. For the political economy approach, non-cooperative actions are a consequence of the spatial economic inequality created by the flow of capital (Pacione 2003), implying that managing blight entails long-term macro and structural reforms. For the self-organisation approach, blight or disorder is emergent. Patterns of blight are borne out of competitive individual interactions in urban space, where the payoffs to cooperative and non-cooperative behaviour are non-equivalent. In this sense governing the problem means altering payoff structures to change behaviour, perhaps through enforcing penalties on non-cooperation (e.g., Vitale 2008).

Table 1 suggests that the problem of blight/ disorder is neither entirely structural (political economy) nor fully behavioural (self-organisation). Instead, by synthesising these two worldviews within an evolutionary perspective, one can argue that poverty creates a function for blight or disorder in an urban environment. This means that the property maintenance behaviour responsible for such outcomes is an adaptive strat-

Table 1. An evolutionary urban geography explanation of urban blight/disorder

\begin{tabular}{|c|c|}
\hline Evolutionary concept & Description \\
\hline Synopsis & $\begin{array}{l}\text { Patterns of blight/disorder reflect the simultaneous operation of individual } \\
\text { and group selection. Household non-cooperative behaviour (deficient property } \\
\text { maintenance) increases individual quality of life by decreasing upkeep costs, } \\
\text { while it decreases neighbourhood order or social control. Low neighbour- } \\
\text { hood order commands low prices in the housing market, and so economically } \\
\text { deprived households tend to sort into disorderly spaces. This sorting process } \\
\text { facilitates geographic variation in order/disorder throughout an urban area. }\end{array}$ \\
\hline Focal unit of selection & Particle (household) \\
\hline Individual trait & Non-cooperative behaviour (deficient maintenance) \\
\hline Measure of individual fitness & Quality of life (QoL) \\
\hline $\begin{array}{l}\text { Individual trait's impact on } \\
\text { fitness }\end{array}$ & $\begin{array}{l}\text { The relationship between household QoL and non-cooperative behaviour is } \\
\text { non-zero and positive; households that underinvest in property maintenance do } \\
\text { so because the decision yields immediate benefits (e.g., cost deferment) }\end{array}$ \\
\hline Heritability of individual trait & Trait is heritable: household cooperative behaviour exhibits path-dependency \\
\hline Group trait & Non-cooperative behaviour \\
\hline Measure of group fitness & Order/social control \\
\hline $\begin{array}{l}\text { Group trait's impact on individ- } \\
\text { ual fitness }\end{array}$ & $\begin{array}{l}\text { The impact of neighbourhood non-cooperative behaviour on household QoL is } \\
\text { non-zero; for relatively wealthy households the relationship is negative, which } \\
\text { gives rise to out-migration (capital mobility) }\end{array}$ \\
\hline $\begin{array}{l}\text { Group trait's impact on group } \\
\text { fitness }\end{array}$ & $\begin{array}{l}\text { Negative: greater collective non-cooperation leads to more disorder/less social } \\
\text { control }\end{array}$ \\
\hline Heritability of group trait & $\begin{array}{l}\text { Collective (neighbourhood) trait is heritable; spatial externalities give rise to new } \\
\text { particles (non-cooperators) in the population }\end{array}$ \\
\hline Ultimate cause & $\begin{array}{l}\text { The housing market places a significant discount on homes in blighted/disor- } \\
\text { derly neighbourhoods, which makes housing therein affordable for economical- } \\
\text { ly deprived households }\end{array}$ \\
\hline Proximate cause(s) & $\begin{array}{l}\text { Deficient property maintenance; positive assortment into orderly/disorderly } \\
\text { neighbourhoods via housing transactions means that economically deprived } \\
\text { households voluntarily trade off more order for cheaper housing; such "individ- } \\
\text { ual passivity" promotes more non-cooperative property maintenance behaviour, } \\
\text { which begins to lock disorder into affected neighbourhoods }\end{array}$ \\
\hline
\end{tabular}


egy for a subset of entities in the population (e.g., Grigsby et al. 1987). More precisely, the ability of poorly maintained urban spaces to host low-cost housing that supports economically disadvantaged households can be reasoned to ultimately cause blight or disorder (Weaver, Bagchi-Sen [in press]). At the same time, the key proximate cause from this explanation is deficient property maintenance (Brueckner, Helsley 2011). Deficient maintenance, in turn, generates negative spatial externalities, and patterns of household-level responses to those externalities produce changes in the presence of non-cooperative property maintenance behaviour at the population level (Weaver, Bagchi-Sen [in press]).

To explore this evolutionary outcome in greater detail, observe first that households in urban areas reside in hierarchically organised populations, such that household "fitness" is a function of both household- and neighbourhood-level attributes (Pacione 2003). One can reasonably assume that household fitness depends on both the household's own non-cooperative behaviour, as well as the non-cooperative behaviour of its neighbours (e.g., Bourne 1981). For non-cooperative households, underinvesting in property maintenance presumably yields immediate utility gains, such as lowering housing expenditures and thus freeing up income for other purposes (Megbolugbe et al. 1996). Simultaneously, non-cooperative households can free-ride on, or enjoy the benefits of, the pro-social maintenance behaviours of its cooperative neighbours.

At the neighbourhood level, fitness (e.g., quality) varies and is differentially impactful on household utility across space (e.g., Skogan 1986). As the political economy explanation suggests, manifestations of decline (blight/disorder) negatively affect the utility of some households in a given neighbourhood, which in turn incentivises them to relocate (Grigsby et al. 1987). This "retreat of capital" leads to concentrations of blight and decline in affected neighbourhoods (Pacione 2003; Weaver, Bagchi-Sen [in press]). Therein, property values, and by extension housing costs, spiral downward (Glaeser, Gyourko 2005). The residual and entrant economically deprived households in such neighbourhoods then receive relatively low-cost housing in exchange for occupying blighted territories (Grigs- by et al. 1987). If one assumes that low housing expenditures contribute positively to individual fitness for deprived households, then it is clear why low-quality neighbourhoods are frequently described as having "individual passivity, weak informal social control, and collective incapacity" with respect to neighbourhood decline (Skogan 1986). In evolutionary parlance, non-cooperation leading to blight/disorder is an adaptation to an urban environment characterised by economic inequality. As stated above, then, the functional basis, or ultimate cause, of urban blight/disorder is that it makes housing affordable for economically deprived households (Weaver, Bagchi-Sen [in press]). As a result, housing transactions facilitate positive assortment into relatively high- and low-quality neighbourhoods based on willingness (ability) to pay for certain neighbourhood conditions. These sorting patterns gradually lock in patterns of non-cooperative property maintenance behaviour across an urban area (e.g., Skogan 1986). It follows that the attribute value of a given property (cooperative or non-cooperative) is path-dependent, and will tend to resemble the state of the property at some prior point in time (e.g., Weaver, Bagchi-Sen [in press]).

Joining this observation to the self-organisation explanation of blight or disorder, uncontrolled increases in within-neighbourhood non-cooperative behaviour stemming from this "individual passivity" can eventually spill over to relatively cooperative neighbourhoods (Skogan 1986; Weaver, Bagchi-Sen 2013). That is, sufficiently powerful between-neighbourhood effects can change the composition of relatively high-quality neighbourhoods through the defection or departure of nearby co-operators in the urban environment (Bourne 1981). Crucially, this implies that non-cooperation at the collective level (the "group trait") is also heritable, in the sense that household decisions are dependent upon encroaching neighbourhood characteristics - collectives give rise to new particles (Megbolugbe et al. 1996; Weaver, Bagchi-Sen [in press]). With that it can be claimed that the Lewontin (1970) conditions are satisfied for two levels of a hierarchically structured urban population (Table 1). Accordingly, multilevel evolutionary forces presumptively operate on housing maintenance behaviour in urban societies. 
To the extent that the evolutionary urban geography framework accounts for both functional and mechanistic sources of blight/disorder, it opens up the possibility for policymakers to become "wise managers" of the evolutionary processes that it describes (e.g., Wilson 2007: 11). At present, urban policymakers in westernised cities largely respond to the problems of blight and disorder by increasing the cost of non-cooperative maintenance behaviour, particularly by punishing non-cooperators through monetary or other penalties (Vitale 2008). Such punitive approaches tend to be socially exclusive and "privilege majoritarian views of appropriate public behaviour" (Vitale 2008: 13). In addition, they outwardly hint at an unawareness of the problem's ultimate cause, as established above. For, so long as blight/disorder serves the functional purpose of creating spaces of low-cost housing that support low-income households in urban systems, imparting economic or physical sanctions on (often resource-limited) non-cooperators will likely exacerbate underlying issues of economic inequality in a particular urban area (e.g., Vitale 2008).

Taking this into consideration, evolutionary urban geography recommends that for a policy intervention to succeed, it must make cooperation a selectively advantageous action. For reasons articulated in the preceding paragraph, exclusively punitive measures do not stand up to this task. Accordingly, while macro and structural reforms are important for addressing longterm economic inequality (e.g., Pacione 2003), immediate attention might be usefully directed to the environment in which blight and disorder evolves. For example, some U.S. and Western European cities have successfully implemented programs to shift urban power relations in ways that grant decision-making authority to citizen leaders in blighted communities (Shlay, Whitman 2006; Wagenaar 2007). Others have designed multi-pronged programs to provide households with options from which they can self-select into a cooperative strategy, and to leverage public and private resources to rehabilitate properties occupied by low-income and disadvantaged households (Weaver 2013). Based on the initial successes of these approaches (e.g., Shlay, Whitman 2006; Wagenaar 2007; Weaver 2013), it is highly probable that jointly attending to structural (ulti- mate: e.g., power relations) and behavioural matters (proximate: e.g., self-selection into cooperative strategies) is the path to improving upon the evolutionary outcomes described in this section. Having said that, by reframing and synthesising existing causal explanations of blight and disorder, evolutionary urban geography offers valuable insights for becoming "wise(r) managers of evolutionary processes" (Wilson 2007: 11). I submit that this result is not unique to issues relating to urban decline, but that it can be realised for research questions in urban geography writ large.

\section{Conclusions}

Despite growing interest in the application of Darwinian evolutionary concepts and ideas to contemporary research questions in human geography, the literature is largely characterised by isolated metaphors and analogies that tend to be disconnected from a broader evolutionary theoretical framework (Jeffrey 1996; Boschma, Frenken 2006). While this under-appreciation of evolutionary theory is observable in economic geography (Essletzbichler, Rigby 2007: 566), in urban geography even these isolated metaphorical appeals, notwithstanding a general evolutionary framework, are mostly unassembled. In this paper I attempt to demarcate, and illustrate the potential of, an "evolutionary urban geography" by outlining the elements and relationships that are thought to be essential ingredients of a general evolutionary framework for inquiries into urban spatial phenomena. Observations about the spatially interdependent nature of urban households and neighbourhoods suggest that such a framework be grounded in Darwinian and multilevel selection theories. This essay accordingly synthesises key components from these theories in an application to the issues of urban blight and disorder, to showcase how an evolutionary perspective produces new insights for managing complex urban problems. Nevertheless, this is merely one modest step toward a general Evolutionary Urban Geography, and future research is needed both to further develop its theoretical foundations, and to empirically "demonstrate the utility of the evolutionary toolkit" (Wilson, Gowdy 2013: 7). 


\section{References}

Allen P., 1997. Cities and regions as self-organizing systems. Taylor, Francis, New York.

Batty M., Xie Y., 1999. Self-organized criticality and urban development. Discrete Dynamics in Nature and Society 3: 109-124.

Boschma R.A., Frenken K., 2006. Why is economic geography not an evolutionary science? Towards an evolutionary economic geography. Journal of Economic Geography 6: 273-302.

Bourne L., 1981. The geography of housing. V.H. Winston \& Sons, Toronto.

Bowles S., 2006. Policies designed for self-interested citizens may undermine 'the moral sentiments': Evidence from economic experiments. Science 320: 1605-1609.

Brueckner J., Helsley R., 2011. Sprawl and blight. Journal of Urban Economics 69(2): 205-213.

Dawkins R., 2003. Introduction. In: Darwin C., The origin of species and the Voyage of the Beagle: with an introduction by Richard Dawkins. Everyman's Library/Random House, New York: ix-xxx.

Dunbar R.I.M., 2007. Evolution and the social sciences. History of the Human Sciences 20(2): 29-50.

Essletzbichler J., Rigby D.L., 2007. Exploring evolutionary economic geographies. Journal of Economic Geography 7: 549-571.

Galster G.C., Cutsinger J.M., Malega R., 2006. The social costs of concentrated poverty: Externalities to neighbouring households and property owners and the dynamics of decline. National Poverty Centre Working Paper Series \#06-42.

Ghitter G., Smart A., 2009. Mad cows, regional governance, and urban sprawl: Path dependence and unintended consequences in the Calgary region. Urban Affairs Review 44(5): 617-644.

Gintis H., Bowles S., Boyd R., Fehr E. (eds), 2005. Moral sentiments and material interests: The foundations of cooperation in economic life. MIT Press, Cambridge.

Glaeser E.L., Gyourko J., 2005. Urban decline and durable housing. Journal of Political Economy 113(2): 345-375.

Grigsby W.G., Baratz M., Maclellan D., 1987. The dynamics of neighbourhood change and decline. Pergamon, Oxford.

Hardin G., 1968. The tragedy of the commons. Journal of Natural Resources Policy Research 1(3): 243-253.

Harvey D., 1976. Class structure in a capitalist society and the theory of residential differentiation. In: Peel R., Chisholm M., Haggett P. (eds), Processes in physical and human geography. Heinemann, London: 354-383.

Heinrich J., et al. (eds), 2004. Foundations of human sociality. Oxford University Press, Oxford.

Hodgson G.M., Knudsen T., 2010. Darwin's conjecture: The search for general principles of social E economic evolution. The University of Chicago Press, Chicago.

Hoyt H., 1939. The structure and growth of residential neighbourhoods in American cities. Federal Housing Administration, Washington, DC.

Jeffrey P., 1996. Evolutionary analogies and sustainability. Futures 28(2): 173-187.

Krumm R., Vaughan R.J., 1976. The economics of urban blight. RAND Washington, DC.

Lewontin R.C., 1970. The units of selection. Annual Review of Ecology and Systematics 1: 1-18.
Lloyd E., Wilson D.S., Sober E., 2011. Evolutionary mismatch and what to do about it: A basic tutorial. The Evolution Institute, Wesley Chapel, FL.

Lustick I.S., 2011. Taking evolution seriously: Historical institutionalism and evolutionary theory. Polity 43(2): 179-209.

Mayr E., 2001. What evolution is. Basic Books, New York.

Megbolugbe I.F., Hoek-Smit M.C., Linneman P.D., 1996. Understanding neighbourhood dynamics: A review of the contributions of William G. Grigsby. Urban Studies 33(10): 1779-1795.

Okasha S., 2006. Evolution and the levels of selection. Clarendon, Oxford.

Pacione M., 2003. Quality-of-life research in urban geography. Urban Geography 24: 314-339.

Pitkin W., 2001. Theories of neighborhood change: Implications for community development policy and practice. UCLA Advanced Policy Institute, Los Angeles.

Pumain D., 1998. Urban research and complexity. In: Bertuglia C.S., Bianchi G., Mela A. (eds), The city and its sciences. Physica-Verlag, Heidelberg: 323-361.

Ross C.E., Mirowsky J., 1999. Disorder and decay: The concept and measurement of perceived neighbourhood disorder. Urban Affairs Review 34: 412-432.

Shlay A., Whitman, G. 2006. Research for democracy: Linking community organizing and research to leverage blight policy. City \& Community 5(2): 153-171.

Skogan W., 1986. Fear of crime and neighbourhood change. Crime and Justice 8: 203-229.

Somerville P., van Beckhoven E., van Kempen R., 2009. The decline and rise of neighbourhoods: The importance of neighbourhood governance. European Journal of Housing Policy 9(1): 25-44.

Torrens P.M., 2006. Simulating sprawl. Annals of the Association of American Geographers 96(2): 248-275.

Van den Bergh J.C.J.M., Gowdy J.M., 2009. A group selection perspective on economic behaviour, institutions, and organization. Journal of Economic Behaviour and Organization 72: 1-20.

Vitale A.S., 2008. City of disorder: How the quality of life campaign transformed New York politics. New York University Press, New York.

Wagenaar H., 2007. Governance, complexity, and democratic participation: How citizens and public officials harness the complexities of neighbourhood decline. The American Review of Public Administration 37(1): 17-50.

Weaver R.C., 2013. Re-framing the urban blight problem with trans-disciplinary insights from ecological economics. Ecological Economics 90: 168-176.

Weaver R.C., Bagchi-Sen S., 2013. Spatial analysis of urban decline: The geography of blight. Applied Geography 40: 61-70.

Weaver R.C., Bagchi-Sen S. [in press]. Evolutionary analysis of neighbourhood decline using multilevel selection theory. The Annals of the Association of American Geographers.

Wilson D.S., 2004. What is wrong with Absolute Individual Fitness? Trends in Ecology and Evolution 19(5): 245-248.

Wilson D.S., 2007. Evolution for everyone: How Darwin's theory can change the way we think about our lives. Delta, New York.

Wilson D.S., 2011. The neighbourhood project: Using evolution to improve my city, one block at a time. Little, Brown, Company, New York, NY. 
Wilson D.S., Wilson E.O., 2007. Rethinking the theoretical foundation of sociobiology. The Quarterly Review of Biology 82(4): 327-348.

Wilson D.S., Gowdy J.M., 2013. Evolution as a general theoretical framework for economics and public policy. Journal of Economic Behaviour and Organization. DOI: 10.1016/j.jebo.2012.12.008.
Wilson D.S., Ostrom, E., Cox M.E., 2013. Generalizing the core design principles for the efficacy of groups. Journal of Economic Behaviour and Organization. DOI: 10.1016/j. jebo.2012.12.010.

Witt U., 1997. Self-organization and economics - What is new? Structural Change and Economic Dynamics 8: 489-507.

Wyly E.K., 1999. Continuity and change in the restless urban landscape. Economic Geography 75(4): 309-338. 